\title{
Pengaruh Posisi Ergonomis Terhadap kinerja Perawat
}

\author{
Sri Rezeki Silalahi
}

\author{
srisilalahi2604@gmail.com
}

\section{Latar Belakang}

Ergonomi adalah ilmu mengenai teknologi terkait desain kerja berdasarkan ilmu biologi manusia, yaitu anatomi, fisiologi dan psikologi dengan tujuan untuk menurunkan tingkat risiko cidera dan meningkatkan motivasi dalam bekerja serta sekaligus meningkatkan produktivitas dari aktivitas pekerjaan dalam suatu stasiun kerja. Salah satu risiko ergonomi yang menyebabkan cidera tubuh akibat kerja adalah Musculoskeletal Disorders (MSDs). Keluhan muskuloskeletal merupakan keluhan pada bagian otot skeletal atau otot rangka yang dirasakan oleh seseorang mulai dari keluhan sangat ringan hingga sangat sakit. Apabila otot menerima beban statis secara berulang dan dalam jangka waktu cukup lama maka akan dapat menyebabkan keluhan berupa kerusakan pada sendi, ligamen dan tendon. Semakin besar nilai risiko ergonomi maka semakin besar pula kemungkinan terjadinya keluhan nyeri otot baik dalam jangka pendek maupun dalam jangka panjang. Semakin lama pekerja bekerja dengan postur janggal, semakin banyak energi yang dibutuhkan untuk mempertahankan kondisi tersebut sehingga dampak kelelahan yang ditimbulkan semakin kuat dan menyebabkan keluhan nyeri otot. Faktor penyebab terjadinya keluhan muskuloskeletal adalah peregangan otot yang berlebihan, aktivitas berulang, sikap kerja tidak alamiah, penyebab sekunder dan penyebab kombinasi. Dan akibat posisi ergononomi yang salah juga dapat menyebabkan salah satu nyeri yang banyak terjadi di dunia yaitu low back pain (LBP). Nyeri ini biasanya dirasakan di daerah lumbal atau lumbosakral.

Lingkungan kerja merupakan tempat dimana seseorang melakukan pekerjaan. Banyak faktor bahaya di lingkungan kerja yang dapat mengakibatkan gangguan kesehatan dan faktor psikososial karyawan. Faktor bahaya tersebut bersumber dari kegiatan dimana proses produksi berlangsung. Lingkungan dan kondisi kerja yang tidak sehat merupakan beban tambahan kerja bagi karyawan. Bahaya faktor psikososial di tempat kerja dapat berhubungan dengan lingkungan sosial kerja, yang berpotensi menyebabkan gangguan pada psikologi dan fisik-fisiologis karyawan. Kondisi kerja yang telah berubah, dampak pada faktor risiko 
psikososial telah meningkat maka kinerja karyawan akan semakin rendah. Psikologis tuntutan pekerjaan adalah salah satu risiko psikososial utama dalam pekerjaan dan mengacu pada aspek pekerjaan yang akan membutuhkan usaha mental atau emosional. Meskipun tidak selalu negatif, tuntutan pekerjaan psikologis dapat memicu reaksi ketegangan dan stres ketika mereka membutuhkan terlalu banyak usaha. Jika berkelanjutan, psikologis tuntutan pekerjaan dapat mengakibatkan sakit (Niedhammer, Chastang, Sultan-Taieb, Vermeylen, \& ParentThirion, 2012).

\section{Metode}

Metode yang digunakan menganalisis jurnal, e-book yang relevan dan berfokus pada karakteristik dan factor yang berhubungan dengan diagnose keperawatan. Selain itu juga saya membaca dan memadukan beberapa e-book dan jurnal yang saya baca dari internet. Metode dari salah satu jurnal yaitu studi kasus dengan menggunakan pendekatan kualitatif, yakni agar dapat memperoleh pemahaman menyeluruh dan utuh tentang fenomena yang diteliti Pendekatan penelitian ini menggunakan pendekatan studi kasus kelompok. Dari jurnal yang lain menggunakan penelitian kuantitatif dengan desain studi cross sectional, pra eksperimen dengan one group pre post test design. Tahap pertama, dilakukan pengamatan sikap atau posisi duduk dengan software OWAS dan dilakukan pengukuran kelelahan kerja dengan reaction timer. Kemudian responden diminta mengisi kuesioner pre test Nordic Body Map tentang keluhan kelelahan yang dirasakan pada anggota tubuh. Jurnal yang lain menggunakan pendekatan kuantitatif, menggunakan metode kualitatif yaitu pengamatan (observasi lapangan), wawancara mendalam, atau penelaahan dokumen. Metode kualitatif digunakan untuk memahami fenomena tentang apa yang dialami oleh subjek penelitian secara holistik, dan dengan cara deskripsi dalam bentuk kata-kata dan bahasa, kemudian menggunakan metode rancangan penelitian Deskriptif Kuantitatif dengan menggunakan pendekatan Cross Sectional atau desain studi potong lintang, dimana proses pengumpulan atau pengambilan data dan pengukuran variabel-variabelnya dilakukan pada satu waktu yang bersamaan.

\section{Hasil}

Hasil penelitian ini sejalan dengan penelitian Zaki (2015), yang mendapatkan bahwa insiden tertinggi LBP terjadi pada kelompok umur 36-45 tahun, sedangkan yang terendah pada kelompok umur 18-25 tahun. Hasil serupa didapat oleh Djais (2013), dimana puncak kejadian LBP pada laki-laki dengan usia rata-rata $45 \pm 13,9$ tahun. Peneliti Berasumsi bahwa dengan bertambahnya umur seseorang akan mengalami penurunan kapasitas fisik dan 
kemampuan fungsionalnya. Jadi semakin tua seseorang, semakin tinggi risiko orang tersebut untuk mengalami nyeri punggung bawah hal ini terjadi karena penurunan elastisitas pada tulang, yang menjadi pemicu timbulnya gejala gangguan musculoskeletal. Berdasarkan hasil penelitian yang telah dilakukan pada pegawai di STIKes Muhammadiyah Palembang, terdapat hubungan posisi duduk dengan Low Back Pain (LBP). posisi duduk dapat menyebabkan Low Back Pain (LBP) disebabkan karena Posisi duduk yang salah dan kurang ergonomis seperti duduk dalam posisi membungkuk dapat memicu kerja otot yang kuat dan lama sehingga aliran darah ke otot terhambat. Dan dari observasi yang dilakukan oleh peneliti didapatkan bahwa beberapa kursi yang ada tidak sesuai standar ergonomic hal ini juga lah yang dapat memicu posisi duduk yang salah dan tidak ergonomic. didapatkan juga hasil umur responden. Pada saat menulis dan membaca dengan menggunakan meja dan kursi yang lama posisi kaki dan tungkai tidak alamiah. Untuk membuat posisi duduk menjadi stabil atau nyaman mereka cenderung melakukan posisi duduk yang tidak alamiah dengan cara menyandarkan pergelangan kedua kakinya di atas alas duduk teman di depannya. Posisi duduk seperti ini dapat terjadi sebagai akibat adanya ketidaksesuaian antropometri dengan ukuran kursi yang digunakan. Akibat posisi duduk yang tidak alamiah tersebut dapat menyebabkan merasa nyeri dan lelah pada bagian tungkai kaki, pergelangan kaki, paha, dan betisnya. Hasil penelitian juga menunjukkan bahwa pekerja dengan keluhan nyeri kaki berat sebagian besar memiliki skor postur kerja berdiri risiko tinggi, sedangkan pekerja dengan keluhan nyeri kaki ringan lebih banyak memiliki skor postur kerja berdiri dengan kategori risiko sedang. Berdasarkan hasil uji statistik dapat disimpulkan bahwa terdapat hubungan antara postur kerja berdiri dengan keluhan nyeri kaki. Berdiri dalam waktu yang lama dapat mengakibatkan perubahan pada sistem tubuh.

Berdasarkan aspek lingkungan kerja dapat dikatakan bahwa faktor fisik dan faktor kimia di lingkungan kerja dapat menimbulkan faktor psikososial bagi karyawan. Faktor fisik tersebut antara lain noise (suara bising), temperature (suhu), clean lines (kebersihan tempat kerja), faktor kimia dust (debu) dan gas. Beberapa permasalahan dalam lingkungan kerja fisik mempengaruhi kesehatan karyawan sehingga memunculkan simptom-simtom gangguan kesehatan mulai dari yang ringan hingga berat Bahaya psikososial adalah suatu bahaya non fisik yang timbul karena adanya interaksi dari aspek-aspek pekerjaan seperti desain kerja, tuntutan kerja, organisasi dan manajemen di tempat kerja serta konteks lingkungan sosial yang berpotensi menimbulkan gangguan bagi kesehatan para pekerja secara fisik, sosial dan psikologi. Bahaya psikososial dapat disimpulkan menjadi beberapa aspek berdasarkan 
kategori karakteristik kerja, organisasi dan lingkungan kerja dimana dapat menyebabkan gangguan kesehatan. Hal ini menunjukkan bahwa karakteristik kerja dapat digunakan untuk menggambarkan bahaya kaitannya dengan hubungan kerja atau isi dari pekerjaan. Kondisi yang tak pasti dari aspek kerja dapat menimbulkan stress dan berbahaya bagi kesehatan. Permasalahan-permasalahan terkait kondisi fisik kerja ini harus diperbaiki oleh perusahaan karena banyaknya konsekuensi negatif yang muncul. Beberapa di antaranya adalah penuruhan kualitas kerja karyawan karena penurunan kualitas kesehatan

\section{Pembahasan}

A. Upaya mempertahankan ergonomik pada posisi berbaring, duduk, berdiri dan berjalan

Duduk merupakan salah satu sikap tubuh menopang batang badan bagian atas oleh pinggul dan sebagian paha yang terbatas pergerakannya. Bila aktivitas atau pekerjaan tidak dilakukan secara ergonomis akan menyebabkan tubuh menjadi tidak nyaman dapat pula meningkatkan resiko timbulnya nyeri punggung. Posisi dan lama duduk dalam bekerja sering diabaikan, padahal kondisi ini penting karena mengandung prinsip ergonomik. Posisi duduk mempengaruhi risiko Low Back Pain (LBP) atau nyeri punggung bawah. Otot yang mengalami kontraksi statis dalam waktu lama juga akan mengalami kekurangan aliran darah dan menyebabkan berkurangnya pertukaran energi dan tertumpuknya sisa-sisa metabolisme pada otot yang aktif, sehingga otot menjadi cepat lelah dan timbul rasa sakit, serta kekuatan kontraksi berkurang yang berakibat produktivitas kerja menurun. Maka sikap kerja yang baik mengupayakan agar postural stress yang muncul sesedikit mungkin.

Keluhan LBP dapat dikurangi dengan model posisi kerja yang ergonomis. Posisi kerja yang ergonomi membuat pekerja merasa nyaman dan tidak menimbulkan rasa lelah. Menurut Grandjen (1993) sebaiknya posisi kerja duduk-berdiri secara bergantian (perubahan posisi) untuk menghindari kejenuhan dan ketegangan otot otot pada anggota tubuh yang statis serta mengubah sikap kerja yang monotoni menjadi lebih bervariasi dan Sanders dan Mc Cormick (1987) memberikan pedoman untuk mengatur ketinggian landasan kerja pada posisi duduk seperti menyediakan meja yang dapat diatur turun dan naik (jika memungkinkan), landasan kerja harus memungkinkan lengan menggantung pada posisi rileks dari bahu, dengan lengan bawah mendekati posisi horisontal atau sedikit menurun (Sloping down slightly) dan ketinggian landasan kerja tidak memerlukan fleksi tulang belakang yang berlebih, Sementara itu postur yang anatomis akan mengurangi kerja dari otot-otot ekstensor 
untuk melawan beban yang ditransmisikan pada tulang belakang. Sehingga kemungkinan terjadinya spasme atau strain pada otot tersebut dapat dihindari. Dan juga, ketika postur dalam posisi anatomis, struktur seperti diskus intervertebralis mendapat pembebanan yang seimbang pada bagian anterior, posterior, dan lateralnya. Sehingga kemungkinan terjadi kerusakan struktur bagian posterior dari tulang belakang yang pain sensitive dapat dicegah.. Contohnya Meja dan kursi yang digunakan harus disesuaikan dengan ukuran antropometri siswa dan sesuai dengan prinsip perancangan yang ergonomis (Santoso, 2012). Kaidah Ergonomi dalam mendesain tempat duduk sangat penting diperhatikan dalam proses pembelajaran. Agar tempat duduk nyaman dipakai pada waktu belajar, maka ukuran-ukurannya harus disesuaikan dengan antropometri orang yang akan memakainya. Penerapan meja dan kursi yang ergonomis dapat mencegah lebih dini berbagai gangguan kesehatan siswa di masa dewasanya nanti dan membentuk sikap tubuh yang benar, mengurangi kelelahan, lebih berkonsentrasi dan akhirnya secara keseluruhan akan dapat meningkatkan sumber daya manusia untuk lebih berkualitas baik dari segi derajat kesehatannya maupun pada peningkatan kemampuan/konsentrasi dalam belajar (Lin, et al., 2014; Santoso, 2012; Sutajaya, 2007).

Sikap kerja berdiri dalam waktu lama akan membuat pekerja selalu berusaha menyeimbangkan posisi tubuhnya sehingga menyebabkan terjadinya beban kerja statis pada otot-otot punggung dan kaki. Kurangnya aliran darah mempercepat timbulnya kelelahan, ketidaknyamanan dan menyebabkan nyeri serta ketegangan pada otototot punggung, kaki dan leher (otot yang digunakan untuk mempertahankan posisi tegak). Berdiri terlalu lama dan sering, tanpa bantuan dengan berjalan kaki, menyebabkan darah berkumpul di kaki. Ketika berdiri terjadi terus menerus selama waktu yang lama, dapat mengakibatkan radang pembuluh darah. Peradangan ini dari waktu ke waktu berkembang menjadi varises kronis dan menyakitkan. Selain itu juga bisa menyebabkan sendi di tulang belakang, pinggul, lutut dan kaki menjadi seperti terkunci yang nantinya memicu terjadinya penyakit rematik degeneratif akibat kerusakan pada tendon dan ligamen (struktur yang mengikat otot tulang).

Upaya mempertahankan posisi ergonomis misalnya melakukan peregangan dan relaksasi ditempat atau sekedar berjalan, mengganti posisi tubuh saat terasa nyeri dengan posisi yang lebih nyaman, menahan rasa nyeri hingga berkesempatan untuk istirahat, dan sebagainya. Dengan kata lain semua pekerja memilliki kemungkinan 
yang sama dalam mengalami rasa nyeri kaki dan yang membedakan ialah faktor individu sendiri

B. Upaya mencegah hazard psikososial

Hazard psikososial merupakan factor dan situasi yang berkaitan dengan tempat kerja atau lingkungan kerja yang dapat memicu stress, ketegangan emosioanl dan masalah interpersonal. Dalam pandangan keselamatan dan kesehatan kerja dapat merupakan tempat beresiko bagi tenaga kerja untuk mengalami gangguan kesehatan atau mengalami kecelakaan kerja. Masalah psikososial merupakan masalah psikis atau kejiwaan yang timbul sebagai akibat terjadinya perubahan social. Bahaya psikososial dapat menyebabkan stres pada pekerja, hal ini dapat disebabkan oleh akumulasi stressor pada situasi kerja di tempat kerja. Misalnya, tuntutan pekerjaan dapat memicu timbulnya stres di tempat kerja. Menurut Randall R. Ross (1994), disebutkan bahwa stres kerja terjadi akibat adanya interaksi antara kondisi kerja dengan karakteristik pekerja dimana tuntutan pekerjaan melebihi kemampuan para pekerja. Oleh karena itu, masalah atau bahaya psikososial dapat terjadi sebagai akibat atau dampak negatif dari adanya proses interaksi sosial seseorang yang buruk. Resiko kerja dan gangguan kesehatan tersebut dapat merugikan para pekerja, yang dapat mengakibatkan pekerja meninggal, keracunan, cacat dan mengidap penyakit kronis sehingga tidak mampu lagi untuk bekerja. Dari bahaya tersebut bahaya terpajan bahaya psikososial dapat dipastikan akan dihadapi oleh seluruh tenaga kerja yang dapat menimbulkan stress kerja dan menjadi masalah bagi kesehatan dan keselamatan kerja.

Upaya mencegah hazards keselamatan kerja dan lingkungan dalam area lingkungan kerja, perawat penting untuk mengidentifikasi agent yang berkaitan dengan pekerjaan dan paparan yang dapat berpotensi sebagai hazard. Upaya mencegah hazard psikososial ada pencegahan primer, sekunder dan tersier. Pencegahan primer yaitu perawat kesehatan kerja dilibatkan dalam upaya promosi kesehatan maupun pencegahan penyakit. Pengenalan terhadap resiko kesehatan ini diikuti oleh berbagai langkah. Perawat kesehatan kerja menggunakan metode yang bervariasi untuk pencegahan primer, dengan interaksi one-one sebagai sebuah strategi yang sangat penting dalam mengevaluasi perilaku penurunan risiko bagi pekerja. Perawat kesehatan kerja merencanakan, mengembangkan, mengimplementasikan, dan mengevaluasi strategi intervensi yang berfokus pada agrerat. Selanjutnya pencegahan sekunder yang ditujukan pada diagnose awal, intervensi penanganan awal. Perawat kesehatan kerja diberikan kesempatan untuk melakukan pengkajian, penilaian dan 
memberikan penanganan serta rujukan pada berbagai kondisi fisik dan psikologis dengan memberikan penanganan atau intervensi langsung pada penyakit. Dan yang terakhir pencegahan sekunder yaitu perawat kesehatan kerja memainkan peran kunci dalam rehabilitasi dan pemulihan pekerjaan dari pekerja untuk mencapai fungsi kesehatan pada tahap level yang optimal. Strategi yang dilakukan termasuk pada managemen kasus, negosiasi, untuk akomodasi tempat konseling serta dukungan untuk pekrja yang mengalami penyakit. Dan tindakan lain yang dapat dilakukan untuk mengatasi hazard psikososial adalah maka perlu dilakukan identifikasi bahaya, dimana penyakit akibat kerja bisa disebabkan oleh perilaku pekerja dan kondisi tempat kerja yang kurang baik.

\section{Penutup}

\section{Kesimpulan}

Terdapat hubungan antara ergonomi kerja terhadap timbulnya gangguan kesehatan akibat kerja, yang mana paling banyak adalah nyeri pinggang, nyeri lutut, dan pusing. Dan faktor ergonomi yang mempengaruhi timbulnya gangguan kesehatan berikutnya adalah perubahan posisi kerja yang sebagian besar tidak mengalami perubahan posisi meskipun terdapat waktu istirahat selama 60 menit tetapi hal tersebut masih dapat menyebabkan kelelahan dan menyebabkan gangguan kesehatan akibat kerja. Kesesuaian antropometri pekerja dengan meja dan kursi perlu diperhatikan agar kegiatan dapat berjalan dengan aman dan nyaman. Sikap duduk ergonomis efektif dapat menurunkan nyeri punggung. Pendidikan dan pelatihan ergonomi dan sikap kerja yang benar harus diperkenalkan di tempat kerja untuk mengurangi resiko keluhan penyakit nyeri pinggang.

Bahaya psikososial yang teridentifikasi pada pekerja adalah risiko stress di tempat kerja berupa hubungan interpersonal dan beban kerja.. Faktor psikososial lingkungan kerja yang ditimbulkan dapat mempengaruhi emosi seseorang antara lain nada suara menjadi tinggi atau keras seperti orang berteriak atau marah-marah saat berbicara dengan orang lain, mudah merasa jengkel atau merasakan perasaan tidak senang dan sulit tidur lelap atau gangguan tidur hal ini disebabkan karena kondisi lingkungan kerja yang bising. Sedangkan suhu panas dan debu dapat menimbulkan efek cepat merasa lelah atau letih. 


\section{Saran}

Diharapkan pekerja ketika melakukan kegiatan tetap memperhatikan posisi yang ergonomi dan pada pihak instalasi mampu memberikan kursi pada pekerja dengan standar kursi yang ergonomis guna mencegah timbulnya kejadian penyakit nyeri punggung dan memanfaatkan waktu istirahat yang diberikan dengan kegiatan yang menyehatkan baik untuk kesehatan kondisi psikologis dan kesehatan tubuh.

Diharapkan pekerja mampu menurunkan hazard psikososial dan perlu dilakukan identifikasi bahaya, dimana penyakit akibat kerja bisa disebabkan oleh perilaku pekerja dan kondisi tempat kerja yang kurang baik. 


\section{Daftar Pustaka}

Andarini Desheila, Pacu Putra, Maya Puspasari, Ani Nidia Listianti, Sasviana Putri. 2019. Indentifikasi Bahaya Psikososial Pada Buruh Wanita di Pabrik Karet. Jurnal Kesehatan No 1https://www.google.com/url?sa=t\&source=web\&rct=j\&url=http://journals.ums.ac.id/index.p hp/JK/article/view/7561\&ved=2ahUKEwiQuffe6Y sAhU4H7cAHd7hA88QFjABegQIARA B\&usg=AOvVaw1i5xSKrKC0WSFcfb3oGdZI\&cshid=1601433051412

Angraika Putri, Anita Apriliany, Dewi Pujiana. 2019. Hubungan Posisi Duduk Dengan Low Back Pain (LBP) Pada Pegawai Stikes. Jurnal Aisyiyah Medika Vol 4(1)

Angrianti Maulina Siska, Bina Kurniawan, Baju Widjasena.2017. Hubungan Antar Postur Kerja Berdiri Dengan Keluhan Nyeri Kaki Pada Pekerja Aktivitas Mekanik Section Welding di PT X. http://ejournal3.undip.ac.id/index.php/jkm

Balaputra ishana, Adi Heru Sutomo. 2017. Pengetahuan Ergonomi dan Postur Kerja Perawat Pada Perawatan Luka Dengan Gangguan Muskuloskletal Di dr.H. Koesnadi Bondowoso. BKM Journal Of Community Medicine And Public Health Vol 33(9)

Daniah, Rizki Zulfikri Fauzi.2016. Hubungan Gejala Stress Dengan Bahaya Psikososial Pada Pekerja Pengumpul Tol Cabang Jagowari Di PT.Jasa Marga (Persero) TBK tahun 2016. Jurnal Ilmu Kesehatan,8(2)

Harwanti Siti, Budi Aji, Nur Ulfah. 2016. Pengaruh Posisi Kerja Terhadap Low Back Pain (LBP) Pada Pekerja Batik Di Kauman Surakarta. Jurnal Kesmas Indonesia Vol 8(1)

Kemala Aliva. 2018. Faktor Psikososial Lingkungan Kerja (Studi Kasus) Pada Karyawan Pabrik SSP PT X. Jurnal Psikologi Vol 11(1) http://www.lib.ui.ac.id/

Nies A Mary, Melanie McEwen. 2019. Keperawatan Kesehatan Komunitas dan kelurga. Singapura: Elsevier

Nilamsari Nefrety, Soebijanto, Lientje, Setokoesoemo.2015. Prototype Bangku Ergonomis Untuk Memperbaiki Posisi Duduk Siswa SMAN di Kabupaten Gresik. Jurnal Ners Vol 1(1)

Primasari Annisa Devi, Hanifa Maher Denny, Ekawati. 2016. Penerapan Hazard Identifiation Risk Assesment And Risk Control (Hirarc) Sebagai Pengendalian Potensi Kecelakaan Kerja Di Bagian Produksi Body Bus PT.X Magelang. Jurnal kesehatan Masyarakat (e-Journal) http://ejournal-s1.undip.ac.id/index.php/jkm 
Simamora, R. H. (2020). Learning of Patient Identification in Patient Safety Programs Through Clinical Preceptor Models. Medico Legal Update, 20(3), 553-556.

Fathi, A., \& Simamora, R. H. (2019, March). Investigating nurses' coping strategies in their workplace as an indicator of quality of nurses' life in Indonesia: a preliminary study. In IOP conference series: Earth and Environmental science (Vol. 248, No. 1, p. 012031). IOP Publishing. 